\title{
Allosteric Indole Amide Inhibitors of p97: Identification of a Novel Probe of the Ubiquitin Pathway
}

Celeste Alverez, ${ }^{\dagger \ddagger}$ Stacie L. Bulfer, ${ }^{\S}$ Ramappa Chakrasali, ${ }^{\|}$Michael. S. Chimenti, ${ }^{\S}$ Raymond J. Deshaies, ${ }^{\perp}$ Neal Green, ${ }^{\#}$ Mark Kelly, ${ }^{\S}$ Matthew G. LaPorte, ${ }^{\ddagger}$ Taber S. Lewis, ${ }^{\ddagger}$ Mary Liang, ${ }^{\dagger,}$ William J. Moore, R. Jeffrey Neitz, ${ }^{\S}$ Vsevolod A. Peshkov, ${ }^{\ddagger}$ Michael A. Walters, $"$ Feng Zhang, ${ }^{\ddagger}$ Michelle R. Arkin, ${ }^{*}, \S$ Peter Wipf, $*, \dagger,+$ and Donna M. Huryn ${ }^{*}, \dagger$,

${ }^{\dagger}$ Department of Pharmaceutical Sciences, University of Pittsburgh, Pittsburgh, Pennsylvania 15261, United States

${ }^{\ddagger}$ University of Pittsburgh Chemical Diversity Center, University of Pittsburgh, Pittsburgh, Pennsylvania 15260, United States

${ }^{\S}$ Department of Pharmaceutical Chemistry, Small Molecule Discovery Center, University of California, San Francisco, California 94158, United States

"Department of Medicinal Chemistry, and the Institute for Therapeutics Discovery and Development, University of Minnesota, Minneapolis, Minnesota 55414, United States

${ }^{\perp}$ Division of Biology and Biological Engineering, California Institute of Technology and Howard Hughes Medical Institute, Pasadena, California 91007, United States

\#Leidos Biomedical Research, Inc., Frederick, Maryland 21702, United States

\section{Supporting Information}

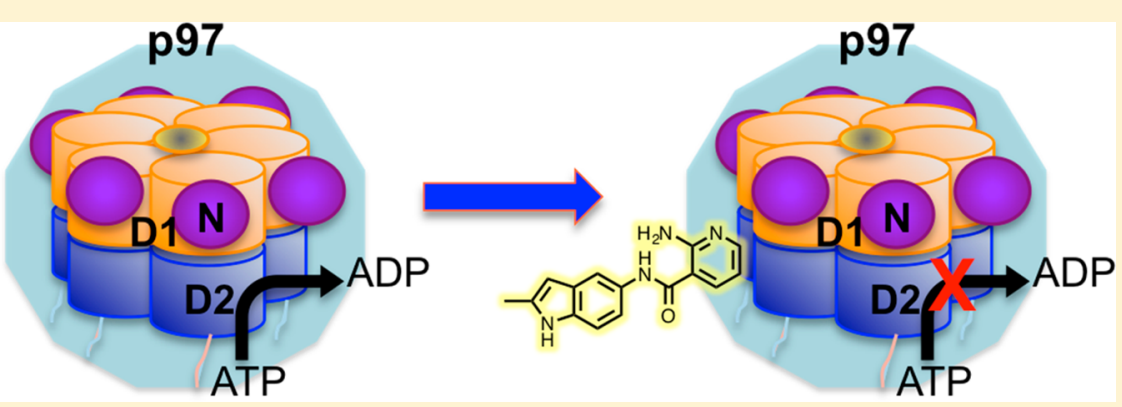

ABSTRACT: A high-throughput screen to discover inhibitors of p97 ATPase activity identified an indole amide that bound to an allosteric site of the protein. Medicinal chemistry optimization led to improvements in potency and solubility. Indole amide 3 represents a novel uncompetitive inhibitor with excellent physical and pharmaceutical properties that can be used as a starting point for drug discovery efforts.

KEYWORDS: AAA ATPase, p97 inhibitor, allosteric inhibitor, indole amide, protein homeostasis, ubiquitin pathway modulator

$\mathrm{T}$ he AAA (ATPase associated with various cellular activities) $\mathrm{p} 97 / \mathrm{VCP}$ is an essential protein in numerous cellular processes and plays a key role in multiple aspects of protein homeostasis. $^{1-3}$ p97 is a homohexamer with each protomer containing a protein-protein interaction domain at the $N$-terminus, a D1 ATPase/hexamerization domain, and the catalytic D2 ATPase domain. While no approved oncology drugs target p97 directly, evidence that inhibiting p97 can be an effective anticancer strategy is mounting. ${ }^{4-6}$ These data include increased levels of p97 in certain cancer patients correlating with poorer clinical outcomes, inhibition of $p 97$ rescuing the tumor suppressor p53 from degradation, and the in vivo efficacy of p97 inhibitors in tumor xenograft models. ${ }^{6,7}$ p97 acts on the pathways thought to be critical for the efficacy of proteasome inhibitors bortezomib and carfilzomib, yet is required for degradation of only a subset of proteasome substrates, suggesting that p97 inhibitors could have improved therapeutic potential in tumor types currently treated by proteasome inhibitors. $^{6,8}$

To date, a number of inhibitors of p97 have been reported; ${ }^{5,9-16}$ those shown in Figure 1 have recently appeared in the literature. Through the auspices of the Molecular Libraries Probe Centers Network, a series of quinazolines, including ML240, were identified and characterized as ATPcompetitive inhibitors. ${ }^{10}$ This scaffold served as the basis for CB-5083, which recently entered Phase I clinical trials. ${ }^{7,16}$ A series of pyrimidines exemplified by $\mathbf{1}$ is likely competitive with ATP, ${ }^{11}$ and the natural product withaferin A was recently reported to exert at least some of its biological effects through

Received: October 8, 2015

Accepted: December 22, 2015

Published: December 22, 2015 

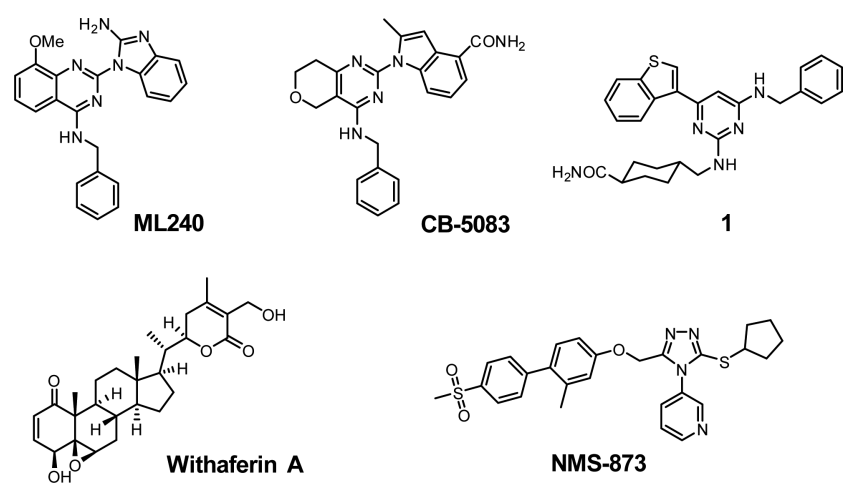

Figure 1. Structures of recently reported p97 inhibitors.

inhibition of $\mathrm{p} 97 .{ }^{12}$ Most relevant to our work is a series of triazoles, represented by NMS-873, which inhibit p97 through an allosteric mechanism. ${ }^{14}$

While NMS-873 exhibits potent biochemical activity and has been used to characterize p97 function, ${ }^{9}$ its poor solubility (7 $\mu \mathrm{M}$ in aqueous $\mathrm{NH}_{4} \mathrm{OAc}$ buffer, $\mathrm{pH}$ 7) prevented our use of it in certain biophysical studies; that limitation along with its metabolic instability reportedly also prevents its use in in vivo experiments. ${ }^{14} \mathrm{We}$ report the development of an indole amide allosteric inhibitor of p97 with improved physicochemical properties compared to NMS-873. By virtue of a combination of potency and improved pharmaceutical properties, this relatively simple scaffold has the potential to serve as a novel tool to explore p97 chemical biology, as well as a starting point for p97 drug discovery.

The indole amide SMDC818909 was discovered as a primary hit in a high throughput screen (HTS) to identify inhibitors of p97 (Figure 2a). ${ }^{17}$ To confirm that this compound
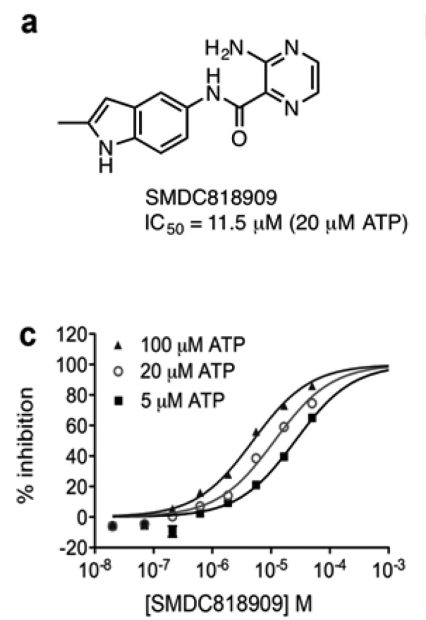

Figure 2. (a) Structure of SMDC818909; (b) binding sensorgram (top) of SMDC818909 and $K_{\mathrm{D}}$ determination (bottom); (c) $\mathrm{IC}_{50}$ determination based on $\%$ inhibition at 5, 20, and $100 \mu \mathrm{M} \mathrm{ATP;} n=2$ at each concentration.

bound specifically to full-length p97, we determined the binding constant and stoichiometry by surface plasmon resonance (SPR). The binding sensorgrams for SMDC818909 (Figure 2b, top) were fit with a $1: 1$ equilibrium-binding model to determine a $K_{\mathrm{D}}$ of $9.1 \mu \mathrm{M}$ and a stoichiometry of $1.6: 1$ protomer based on the stoichiometry of ADP binding $^{18}$ (Figure 2b, bottom). A stoichiometry greater than $1: 1$ could be due to some nonspecific binding to p97 at the highest concentration tested. The binding of SMDC818909 was then tested against just the ND1 domains of p $97 .{ }^{18}$ No binding was observed to this ND1 truncation indicating that the catalytic D2 domain is the likely binding site (Figure S1). The kinetic mechanism of inhibition was also evaluated by determining $\mathrm{IC}_{50}$ values at three different ATP concentrations. The $\mathrm{IC}_{50}$ value decreased with increasing ATP concentration $(26.0 \pm 0.9,11.5 \pm 0.9$, and $4.9 \pm 0.9 \mu \mathrm{M}$ at 5 , 20 , and $100 \mu \mathrm{M}$ ATP, respectively), indicating that it behaved primarily uncompetitively with the ATP substrate (Figure 2c).

While SMDC818909 had low micromolar potency, its uncompetitive mechanism was attractive because it could be differentiated from the ATP-competitive inhibitor CB-5083 in the clinic. In general, an uncompetitive inhibitor would not have to compete with high intracellular concentrations of ATP and may be selective versus other enzymes that require ATP. The aqueous solubility of SMDC818909 was modest $(56 \mu \mathrm{M})$, but its low molecular weight $(267 \mathrm{Da})$ and promising properties $\left(\mathrm{PSA}=96 \AA^{2}, \mathrm{LE}=0.38 \mathrm{kcal} / \mathrm{mol} /\right.$ heavy atom, calculated $\log \mathrm{D} \approx 1)^{19}$ as well as the potential to rapidly prepare analogues by retrosynthetic disconnection of the amide linkage, led us to embark on a medicinal chemistry optimization effort. We report here the highlights of these efforts.

Early SAR indicated that each feature of the compact structure contributed to the observed activity. Analogues where the indole moiety was replaced with isosteres were inactive. In addition, replacement of the pyrazine with non-nitrogenous heterocycles or other $\mathrm{N}$-containing rings led to inactivity (Table S1). Within those constraints, our efforts focused on indole amide analogues with the goal of improving potency and pharmaceutical properties.

An initial series of indole amides was prepared via standard amide coupling chemistry as shown in Scheme 1. In many

Scheme 1. General Synthesis of Indole Amides

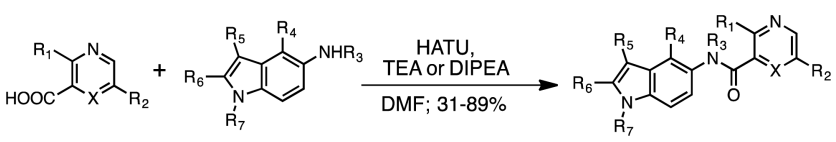

cases, the acid and indole amine starting materials were commercially available or known in the literature; ${ }^{20,21}$ however, in some instances, the prohibitive cost of 5-amino indoles encouraged the use of $\mathrm{C}-\mathrm{H}$ activation methods for preparative access (Supporting Information). ${ }^{22}$

Conservative modification of the amino-pyrazine ring led to the realization that this position was highly sensitive to structural variation (Table 1). Replacement of one of the pyrazine nitrogen atoms, $\mathrm{N}-1$, with a carbon atom afforded the inactive 3 -amino pyridine 2 . In contrast, nitrogen-carbon exchange at the $\mathrm{N}-4$ position provided the 2 -amino pyridine 3 , which was over 4-times more potent than the original hit $\left(\mathrm{IC}_{50}\right.$ $=2.6 \mu \mathrm{M}$ ). Due to the uncompetitive mechanism of inhibition, the assay conditions were modified to employ a higher concentration at ATP $(100 \mu \mathrm{M})$ to ensure consistent and reliable measurements. Under these conditions, $\mathrm{IC}_{50} \mathrm{~s}$ for compound 3 and SMDC818909 were measured at 0.5 and $3.5 \mu \mathrm{M}$, respectively, resulting in a 7 -fold improvement in potency. Removal of the 2 -amino substituent of the pyrazine (4) was also detrimental to activity.

Similarly, modifications to the indole ring were also highly sensitive to structural changes. Substitution at the 3-position 
Table 1. SAR of Indole Amides ${ }^{a}$

\begin{tabular}{|c|c|c|c|}
\hline Entry & Compound & Structure & $\begin{array}{c}\text { p97 ADP-Glo } \\
\text { IC }_{50}[\mu \mathrm{M}]\end{array}$ \\
\hline 1 & NMS-873 & (see Figure 1) & $\begin{array}{c}{[0.011 \pm 0.004} \\
(\mathrm{n}=13)]\end{array}$ \\
\hline 2 & $\begin{array}{l}\text { SMDC } \\
818909\end{array}$ & & $\begin{array}{l}11.5 \pm 4.6(n=15) \\
{[3.5 \pm 1.7(n=18)]}\end{array}$ \\
\hline 3 & 2 & & $>50(\mathrm{n}=2)$ \\
\hline 4 & 3 & & $\begin{array}{c}2.6 \pm 1.8(\mathrm{n}=5) \\
{[0.5 \pm 0.2(\mathrm{n}=22)]}\end{array}$ \\
\hline 5 & 4 & & $>50(\mathrm{n}=1)$ \\
\hline 6 & 5 & & $>50(\mathrm{n}=1)$ \\
\hline 7 & 6 & & {$[>50(n=1)]$} \\
\hline 8 & 7 & & {$[13(n=1)]$} \\
\hline 9 & 8 & & $>50(\mathrm{n}=1)$ \\
\hline
\end{tabular}

${ }^{a}$ Assay conditions: ADP-Glo with $20 \mathrm{nM} \mathrm{WT}$ p97 in the presence of $20 \mu \mathrm{M}$ ATP concentration and/or [100 $\mu \mathrm{M}$ ATP]. $n$ denotes number of independent replicates, each assayed in duplicate or triplicate.

(5) or the indole-nitrogen atom (6) with a methyl group resulted in the complete loss of activity. Modification of the 2position suggested some tolerance for steric bulk. The 2-ethyl analogue 7 exhibited a 3-fold reduction in potency compared to the original methyl analogue, but larger groups (propyl, methylcyclopropyl) on the same scaffold were inactive (data not shown). Removal of the 2-methyl group (8) led to an inactive compound.

The requirement for a small (methyl or ethyl) substituent at the C-2 indole position for activity was consistent with 1-D ${ }^{1} \mathrm{H}$ NMR studies of these analogues' binding to a p97 truncation that contains just the D2 domains. NMR measurements showed line broadening of SMDC818909 resonances upon binding to the D2 domain (Figure 3). In contrast, the inactive unsubstituted analogue 8 did not show any changes in the NMR spectrum in the presence of p97 D2 (Figure S3). For SMDC818909, the strongest intensity changes occurred at the 2-methyl and 3-position protons (designated by a and $b$, respectively), suggesting that these positions are rigidly held in contact with p97.

The promising activity of 3 prompted further SAR exploration that maintained the 2 -amino pyridine and indole scaffolds. Most of these derivatives were synthesized as shown in Scheme 1 using a nicotinic acid derivative and the appropriate indole. When 2-amino-5-bromonicotinic acid was
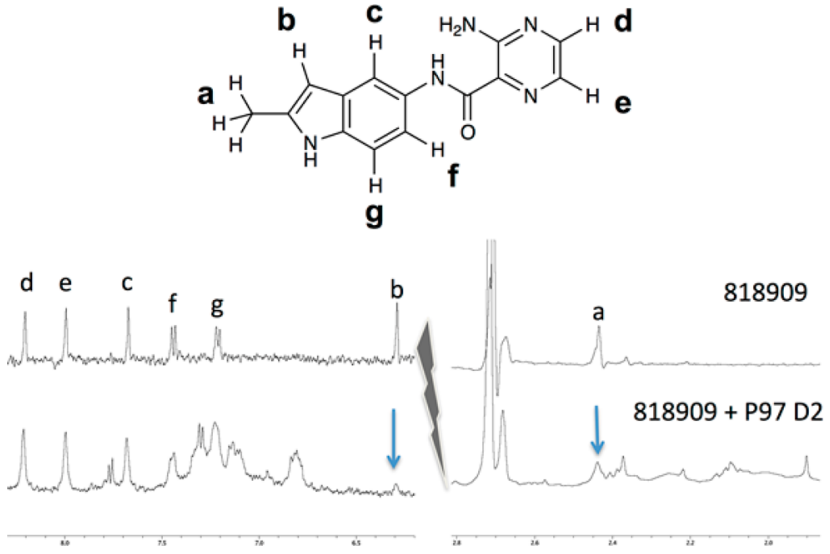

Figure 3. Line-broadening in 1-D ${ }^{1} \mathrm{H}$ NMR of compound in the presence of the p97 D2 domain: $100 \mu \mathrm{M}$ SMDC818909 reference (top) and the same concentration in the presence of $10 \mu \mathrm{M}$ p97 D2 (lower) with signals for protons at C-3 (b) and C-2 $\mathrm{CH}_{3}$ (a) noted by the blue arrows. Bolt denotes break in spectra; intensity to the left of the bolt has been scaled-up relative to the right side.

used (Scheme 1: $\mathrm{X}=\mathrm{C}, \mathrm{R}_{1}=\mathrm{NH}_{2}, \mathrm{R}_{2}=\mathrm{Br}$ ), further manipulation ${ }^{24,25}$ introduced a variety of functional groups such as pyrazole 9, nitrile 10, and ethyl 11 (Scheme 2). Reductive amination of 2-methyl- $1 \mathrm{H}$-indol-5-amine and 2-amino nicotinaldehyde afforded amine $\mathbf{1 2}$ (Scheme S1).

Scheme 2. Synthesis of 4-Substituted Pyridine Indole Amides 9, 10, and 11
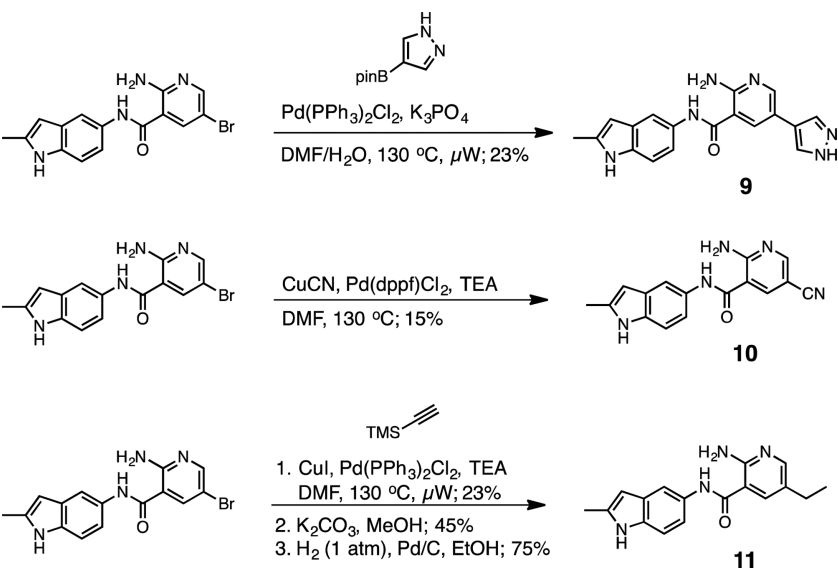

The essential role of the secondary amide was evident by several key SAR insights (Table 2; unless otherwise noted, $\mathrm{IC}_{50} \mathrm{~S}$ at $100 \mu \mathrm{M}$ ATP are reported). The $N$-methyl amide 13/ Entry 3 was completely devoid of activity, and the amine 12/ Entry 4 was $\sim 20$-fold less active than amide 3 . Efforts to replace the amide with a sulfonamide, ester, or a shortened amine linker led to inactive compounds (data not shown). We considered the possibility that hydrolysis of the amide to the constitutive 2-amino nicotinic acid and 2-methyl- $1 \mathrm{H}$-indol-5amine could occur under the assay conditions, and these fragments were responsible for the observed activity. However, both compounds were inactive in the p97 ADP-Glo assay, countering this hypothesis (data not shown).

The SAR trends at the 2-position of the indole were consistent with our previous observations. The ethyl analogue 14/Entry 5 exhibited a 3-fold loss of potency, and larger groups (propyl, 15/Entry 6) showed an even greater diminution. As in 
Table 2. SAR of Pyridine Indole Amides ${ }^{a}$

\begin{tabular}{|c|c|c|c|}
\hline Entry & Compound & Structure & $\begin{array}{l}\text { p97 ADP-Glo } \\
\text { IC }_{50}[\mu \mathrm{M}]\end{array}$ \\
\hline 1 & NMS-873 & (see Figure 1) & $\begin{array}{c}0.011 \pm 0.004 \\
(\mathrm{n}=13)\end{array}$ \\
\hline 2 & 3 & & $\begin{array}{l}0.5 \pm 0.2(\mathrm{n}=22) \\
{[2.6 \pm 1.8(\mathrm{n}=5)]}\end{array}$ \\
\hline 3 & 13 & & $>50(\mathrm{n}=1)$ \\
\hline 4 & 12 & & $10 \pm 1.5(n=4)$ \\
\hline 5 & 14 & & $1.6(n=1)$ \\
\hline 6 & 15 & & $17(\mathrm{n}=1)$ \\
\hline 7 & 16 & & $>50(\mathrm{n}=1)$ \\
\hline 8 & 17 & & $26(n=1)$ \\
\hline 9 & 18 & & $37(\mathrm{n}=1)$ \\
\hline 10 & 11 & & $13 \pm 2.5(n=4)$ \\
\hline 11 & $\begin{array}{c}9 \\
(\mathrm{R}=\text { pyrazol-4-yl }) \\
\mathbf{1 0}(\mathrm{R}=\mathrm{CN})\end{array}$ & & $\begin{array}{l}\text { 9: }>50(n=1) \\
10: 27(n=1)\end{array}$ \\
\hline 12 & $\begin{array}{c}19(\mathrm{R}=\mathrm{H}) \\
20(\mathrm{R}=\mathrm{OH}) \\
21\left(\mathrm{R}=\mathrm{NHCH}_{3}\right)\end{array}$ & & $\begin{array}{l}19:>50(n=1) \\
20:>50(n=1) \\
21:>50(n=1)\end{array}$ \\
\hline
\end{tabular}

${ }^{a}$ Assay conditions: ADP-Glo with $10 \mathrm{nM}$ WT p97 in the presence of $100 \mu \mathrm{M}$ ATP concentration and [20 $\mu \mathrm{M}$ ATP]. $n$ denotes number of independent replicates, each assayed in duplicate or triplicate.

the pyrazine series, complete removal of steric bulk at that position was unfavorable: the unsubstituted analogue 16/Entry 7 was inactive at the highest concentration tested. Additional elaboration indicated further sensitivity to modest structural changes. Methyl substitution at the 4-position of the indole (17/Entry 8) resulted in a significant reduction in potency, which was further eroded with increased steric bulk (18/Entry 9).

Changes to the nicotinic acid group were also investigated. Substitution at the 4-position indicated that small alkyl groups such as ethyl (11/Entry 10) were tolerated but were less active than the unsubstituted analogue. Larger substituents such as a pyrazole (9/Entry 11) or smaller ones with modified polarity or geometric constraints such as the nitrile (10/Entry 11$)$ proved to be less active than the lipophilic ethyl group. The primary amine was essential for activity; removal (19/Entry 12), replacement with $\mathrm{OH}$ (20/Entry 12), or methylation (21/ Entry 12) abolished activity.

In this series, 3 represented the most potent analogue in biochemical assays and provided a $\sim 7$-fold improvement in potency compared to the initial HTS hit. Its aqueous solubility was $330 \mu \mathrm{M}$ (PBS, $\mathrm{pH} 7.4$ ), which constituted a $\sim 6$-fold improvement. $P_{\text {app }}$ values in MDCK bidirectional permeability assays were $71 \times 10^{-6}$ and $46 \times 10^{-6} \mathrm{~cm} / \mathrm{s}$, respectively. While $T_{1 / 2}$ in mouse microsomal stability studies was only $5 \mathrm{~min}$, human $T_{1 / 2}$ was $>60 \mathrm{~min}$.

Similar to SMDC818909, the kinetic model of inhibition for 3 was primarily uncompetitive as determined by measuring the Michaelis-Menten kinetics for p97 at various inhibitor concentrations (Figure 4). The Lineweaver-Burke plot lines
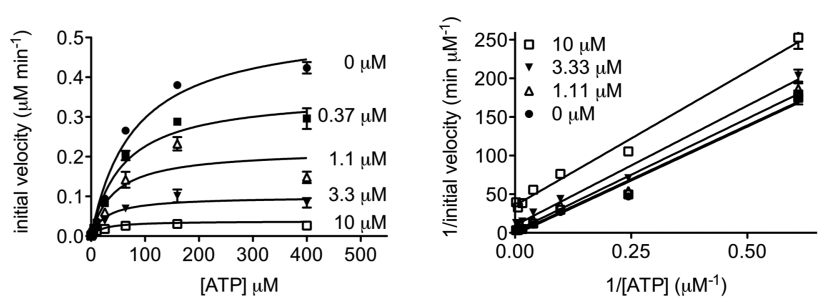

Figure 4. Michaelis-Menten kinetic analysis of p97 in the presence of 3. Data fit to a predominantly uncompetitive mechanism of action.

were nearly parallel but did intersect in the lower-left quadrant (Figure S2), indicating mixed-inhibition with a strong preference for inhibiting the enzyme-substrate complex. Indeed, fitting a mixed-model of inhibition to the data yielded a $K_{i}^{\prime}$ (uncompetitive inhibition) of $0.74 \pm 0.57 \mu \mathrm{M}$ and a weaker $K_{\mathrm{i}}$ (competitive inhibition) of $3.5 \pm 1.7 \mu \mathrm{M}$.

This indole amide displays excellent pharmaceutical properties, including high solubility, permeability, and human microsomal stability. Unfortunately, when tested at concentrations of up to $40 \mu \mathrm{M}, 3$ proved inactive in an assay that monitors $\mathrm{p} 97$-dependent protein degradation $\left(\mathrm{Ub}^{\mathrm{G} 76 \mathrm{~V}}-\mathrm{GFP}\right.$ reporter). ${ }^{26,27}$ In the NCI-60 panel, modest effects $\left(\log \mathrm{GI}_{50} \approx\right.$ $-4.5)$ were seen in a leukemia (RPMI-8226), breast cancer (MDA-MB-468), and melanoma (LOX IMVI) cell lines. It is likely that further improvements in potency will be necessary to see the effects of this scaffold in a cellular setting. In the triazole series of allosteric inhibitors, a "threshold" of $200 \mathrm{nM}$ biochemical potency seemed to be required before cellular effects (antiproliferative activity, accumulation of polyubiquitinated proteins, and p97-dependent biomarker accumulation) were observed. ${ }^{14}$ Given that these indole amides also work through an allosteric mechanism, the lack of robust cellular effects at this stage of optimization may not be surprising. Nonetheless, 3 represents a valuable tool compound that exhibits submicromolar biochemical potency and binds to a defined allosteric site on p97, presumably on the D2 domain, with low stoichiometry. The biochemical characteristics of 3 along with its excellent solubility give it the potential to interrogate p97 structure and function and to serve as a starting point for further drug discovery activities.

\section{ASSOCIATED CONTENT}

S Supporting Information

The Supporting Information is available free of charge on the ACS Publications website at DOI: 10.1021/acsmedchemlett.5b00396. 
Experimental procedures and spectral data for key compounds (PDF)

\section{AUTHOR INFORMATION}

\section{Corresponding Authors}

*E-mail: huryn@pitt.edu (D.M.H.).

*E-mail: michelle.arkin@ucsf.edu (M.R.A.).

*E-mail: pwipf@pitt.edu (P.W.).

\section{Author Contributions}

The manuscript was written through contributions of all authors. All authors have given final approval to the final version of the manuscript.

\section{Funding}

The project was funded in whole or in part with federal funds from the National Cancer Institute, National Institutes of Health, under Chemical Biology Consortium Contract No. HHSN261200800001E Agreement No. 29XS127TO15.

\section{Notes}

The authors declare the following competing financial interest(s): Raymond J. Deshaies is co-founder, shareholder, consultant, and member of the $\mathrm{SAB}$ of Cleave Biosciences, which is developing p97/VCP inhibitors for clinical use.

\section{ACKNOWLEDGMENTS}

The authors gratefully acknowledge our colleagues at the University of Pittsburgh Dr. Chaemin Lim for data retrieval, Ms. Shelby Anderson for compound management and handling, and Mr. Peter Chambers for analytical chemistry support; Dr. Tsui-Fen Chou (UCLA) for Ub-GFP reporter assay data on 3, and Dr. Sean Marcsisin, Dr. Jason Sousa and Ms. Brittney Potter (WRAIR) for pharmaceutical property data. The authors also appreciate the helpful discussion and suggestions of all the CBC p97project team members particularly Eric Baldwin (Leidos), Tsui-Fen Chou, Andrew Flint (Leidos), Gunda Georg (University of Minnesota), Matthew P. Jacobson (UCSF), Barbara Mroczowski (NCI), Shizuko Sei (Leidos), and Gordon Stott (Leidos).

\section{ABBREVIATIONS}

Bpin, (pinacolato)boron; DIPEA, $N, N$-diisopropyl-ethylamine; dppf, 1,1-ferrocenediylbis(diphenylphosphine); ELSD, evaporative light scattering detection; HATU, 1-[bis(dimethylamino)-methylene]-1H-1,2,3-triazolo[4,5-b]pyridinium 3-oxid hexafluorophosphate; TEA, triethylamine; LE, ligand efficiency; MDCK, Madin-Darby canine kidney epithelial cell; PBS, phosphate buffered saline; PSA, polar surface area; VCP, valosin containing protein

\section{REFERENCES}

(1) Woodman, P. G. p97, a protein coping with multiple identities. J. Cell Sci. 2003, 116, 4283-4290.

(2) Wang, Q.; Song, C.; Li, C.-C. H. Molecular perspectives on p97VCP: progress in understanding its structure and diverse structural biological functions. J. Struct. Biol. 2004, 146, 44-57.

(3) Meyer, H.; Bug, M.; Bremer, S. Emerging functions of the VCP/ p97 AAA-ATPase in the ubiquitin system. Nat. Cell Biol. 2012, 14, 117-123.

(4) Chou, T.-F.; Brown, S. J.; Minond, D.; Nordin, B. E.; Li, K.; Jones, A. C.; Chase, P.; Porubsky, P. R.; Stoltz, B. M.; Schoenen, F. J.; Patricelli, M. P.; Hodder, P.; Rosen, H.; Deshaies, R. J. Reversible inhibitor of $\mathrm{p} 97, \mathrm{DBeQ}$ impairs both ubiquitin-dependent and autophagic protein clearance pathways. Proc. Natl. Acad. Sci. U. S. A. 2011, 108, 4834-4839.
(5) Chapman, E.; Maksim, N.; de la Cruz, F.; La Clair, J. J. Inhibitors of the AAA+Chaperone p97. Molecules 2015, 20, 3027-3049.

(6) Valle, C. W.; Min, T.; Bodas, M.; Mazur, S.; Begum, S.; Tang, D.; $\mathrm{Vij}, \mathrm{N}$. Critical role of $\mathrm{VCP} / \mathrm{p} 97$ in the pathogenesis and progression of non-small cell lung carcinoma. PLoS One 2011, 6, e29073.

(7) Zhou, H.-J.; Wang, J.; Yao, B.; Wong, S.; Djakovic, S.; Kumar, B.; Rice, J.; Valle, E.; Soriano, F.; Menon, M.-K.; Madriaga, A.; Kissvonsoly, S.; Kumar, A.; Parlati, F.; Yakes, M. F.; Shawver, L.; Le Moigne, R.; Anderson, D. J.; Rolfe, M.; Wustrow, D. Discovery of a first-in-class, potent, selective and orally bioavailable inhibitor of the p97 AAA ATPase (CB-5083). J. Med. Chem. 2015, DOI: 10.1021/ acs.jmedchem.5b01346.

(8) Deshaies, R. J. Proteotoxic crisis, the ubiquitin proteome system, and cancer therapy. BMC Biol. 2014, 12, 94.

(9) Magnaghi, P.; D’Alessio, R.; Valsasina, B.; Avanzi, N.; Rizzi, S.; Asa, D.; Gasparri, F.; Cozzi, L.; Cucchi, U.; Orrenius, C.; Polucci, P.; Ballinari, D.; Perrera, C.; Leone, A.; Cervi, G.; Casale, E.; Xiao, Y.; Wong, C.; Anderson, D. J.; Galvani, A.; Donati, D.; O’Brien, T.; Jackson, P. K.; Isacchi, A. Covalent and allosteric inhibitors of the ATPase VCP/p97 induce cancer cell death. Nat. Chem. Biol. 2013, 9, $548-556$.

(10) Chou, T.-F.; Li, K.; Frankowski, K. J.; Schoenen, F. J.; Deshaies, R. J. Structure-activity relationship study reveals ML240 and ML241 as potent and selective inhibitors of p97 ATPase. ChemMedChem 2013, $8,297-312$.

(11) Cervi, G.; Magnaghi, P.; Asa, D.; Avanzi, N.; Badari, A.; Borghi, D.; Caruso, M.; Cirla, A.; Cozzi, L.; Felder, E.; Galvani, A.; Gasparri, F.; Lomolino, A.; Magnuson, S.; Malgesini, B.; Motto, I.; Pasi, M.; Rizzi, S.; Salom, B.; Sorrentino, G.; Troiani, S.; Valsasina, B.; O’Brien, T.; Isacchi, A.; Donati, D.; D'Alessio, R. Discovery of 2(cyclohexylmethylamino)pyrimidines as a new class of reversible valosine containing protein inhibitors. J. Med. Chem. 2014, 57, 1044310454.

(12) Tao, S.; Tillotson, J.; Wijeratne, E. M. K.; Xu, Y.; Kang, M.; Wu, T.; Lau, E. C.; Mesa, C.; Mason, D. J.; Brown, R. V.; La Clair, J. J.; Gunatilaka, A. A. L.; Zhang, D. D.; Chapman, E. Withaferin A analogs that target the AAA+ chaperone p97. ACS Chem. Biol. 2015, 10, 1916-1924.

(13) Bursavich, M. G.; Parker, D. P.; Willardsen, J. A.; Gao, Z.-H.; Davis, T.; Ostanin, K.; Robinson, R.; Peterson, A.; Cimbora, D. M.; Zhu, J.-F.; Richards, B. 2-Anilino-4-aryl-1,3-thiazole inhibitors of valosin-containing protein (VCP or p97). Bioorg. Med. Chem. Lett. 2010, 20, 1677-1679.

(14) Polucci, P.; Magnaghi, P.; Angiolini, M.; Asa, D.; Avanzi, N.; Badari, A.; Bertrand, J.; Casale, E.; Cauteruccio, S.; Cirla, A.; Cozzi, L.; Galvani, A.; Jackson, P. K.; Liu, Y.; Magnuson, S.; Malgesini, B.; Nuvoloni, S.; Orrenius, C.; Sirtori, F. R.; Riceputi, L.; Rizzi, S.; Trucchi, B.; O’Brien, T.; Isacchi, A.; Donati, D.; D’Alessio, R. Alkylsulfanyl-1,2,4-triazoles, a new class of allosteric valosine containing protein inhibitors. Synthesis and structure-activity relationships. J. Med. Chem. 2013, 56, 437-450.

(15) Alverez, C.; Arkin, M. R.; Bulfer, S. L.; Colombo, R.; Kovaliov, M.; LaPorte, M. G.; Lim, C.; Liang, M.; Moore, W. J.; Neitz, R. J.; Yan, Y.; Yue, Z.; Huryn, D. M.; Wipf, P. Structure-activity study of bioisosteric trifluoromethyl and pentafluorosulfanyl indole inhibitors of the AAA ATPase p97. ACS Med. Chem. Lett. 2015, 6, 1225.

(16) Anderson, D. J.; Le Moigne, R.; Djakovic, S.; Kumar, B.; Rice, J.; Wong, S.; Wang, J.; Yao, B.; Valle, E.; von Soly, S. K.; Madriaga, A.; Soriano, F.; Menon, M.-K.; Wu, Z. Y.; Kampmann, M.; Chen, Y.; Weissman, J. S.; Aftab, B. T.; Yakes, F. M.; Shawver, L.; Zhou, H.-J.; Wustrow, D.; Rolfe, M. Targeting the AAA ATPase p97 as an approach to treat cancer through disruption of protein homeostasis. Cancer Cell 2015, 28, 653-665.

(17) Manuscript in preparation.

(18) Chou, T.-F.; Bulfer, S. L.; Weihl, C. C.; Li, K.; Lis, L. G.; Walters, M. A.; Schoenen, F. J.; Lin, H. J.; Deshaies, R. J.; Arkin, M. R. Specific inhibition of p97/VCP ATPase and kinetic analysis demonstrate interaction between D1 and D2 ATPase domains. J. Mol. Biol. 2014, 426, 2886-2899. 
(19) Accelrys Software Inc., Chemistry Collection: Basic Chemistry User Guide, Pipeline Pilot; Accelrys Software Inc.: San Diego, 2011.

(20) Kuyper, L. F.; Baccanari, D. P.; Jones, M. L.; Hunter, R. N.; Tansik, R. L.; Joyner, S. S.; Boytos, C. M.; Rudolph, S. K.; Knick, V.; Wilson, H. R.; Caddell, J. M.; Friedman, H. S.; Comley, J. C. W.; Stables, J. N. High-affinity inhibitors of dihydrofolate reductase: antimicrobial and anticancer activities of 7,8-dialkyl-1,3diaminopyrrolo[3,2-f] quinazolines with small molecular size. J. Med. Chem. 1996, 39, 892-903.

(21) Niu, C.; Boschelli, D. H.; Tumey, L. N.; Bhagirath, N.; Subrath, J.; Shim, J.; Wang, Y.; Wu, B.; Eid, C.; Lee, J.; Yang, X.; Brennan, A.; Chaudhary, D. First generation 5-vinyl-3-pyridinecarbonitrile PKC $\theta$ inhibitors. Bioorg. Med. Chem. Lett. 2009, 19, 5829-5832.

(22) Jiao, L.; Bach, T. Palladium-catalyzed direct 2-alkylation of indoles by Norbornene-mediated regioselective cascade C-H activation. J. Am. Chem. Soc. 2011, 133, 12990-12993.

(23) Mayer, M.; Meyer, B. Group epitope mapping by saturation transfer difference NMR to identify segments of a ligand in direct contact with a protein receptor. J. Am. Chem. Soc. 2001, 123, 61086117.

(24) Arndt, J.; Chan, T.; Guckian, K.; Kumaravel, G.; Lee, W.-C.; Lin, E. Y.-S.; Scott, D.; Sun, L.; Thomas, J. Van Vloten, K.; Wang, D.; Zhang, L.; Erlanson, D. Heterocyclic compounds useful as PDK1 inhibitors. WO Patent Appl. 2011044157 A1, April 14, 2011.

(25) Levin, J. I.; Du, M. T.; Venkatesan, A. M.; Nelson, F. C.; Zask, A.; $\mathrm{Gu}, \mathrm{Y}$. The preparation and use of ortho-sulfonamido aryl hydroxamic acids as matrix metalloproteinase and TACE inhibitors. WO Patent Appl. WO1998016503 A2, April 23, 1998.

(26) Chou, T.-F.; Deshaies, R. J. Quantitative cell-based protein degradation assays to identify and classify drugs that target the ubiquitin-proteosome system. J. Biol. Chem. 2011, 286, 16546-16554. (27) Chou, T.-F. Unpublished results. 